\title{
The evaluation of the effect of Sida acuta leaf extract on the microanatomy and some biochemical parameters on the liver of Wistar rats
}

\author{
Kebe. E. Obeten ${ }^{1}$, Kelechi C. Uruakpa, ${ }^{2}$ Victoria Isaac ${ }^{3}$ \\ ${ }_{1,2,3}$ (Department of Anatomy, University of Calabar, Calabar, Nigeria)
}

\begin{abstract}
This study was carried out to evaluate the effect of ethanolic leaf extract of Sida acuta on the microanatomy of the liver and some biochemical parameters in adult Wistar rats. Thirty rats weighing between 140$180 \mathrm{~g}$ were assigned to three groups (A, B and $C)$ with ten animals each. Group A served as the control while groups $B$ and $C$ served as the experimental groups and received $100 \mathrm{mg} / \mathrm{kgbw}$ and $200 \mathrm{mg} / \mathrm{kg} b \mathrm{w}$ of the extract respectively for fourteen days. All the animals were sacrificed after fourteen days. Blood was collected by cardiac puncture for biochemical analysis of serum liver enzymes $s$ The liver was removed, preserved and processed for paraffin sections and hematoxylin and eosin $(H \& E)$ staining. The animals in the control group showed normal histological and biochemical parameters. Conversely, animals that received 100mg/kgbw of the extract showed slight difference in their hepatic cyto-architecture while animals that were administered with $200 \mathrm{mg} / \mathrm{kg} \mathrm{bw}$ of the extract revealed distorted morphological feature showing shrunken sinusoid and dilation of the central vein suggesting that the extract has adverse effect on the morphology of the liver. Results of the serum liver enzymes of animals treated with $100 \mathrm{mg} / \mathrm{kgbw}$ and $200 \mathrm{mg} / \mathrm{kg}$ revealed significantly decreased values of AST, ALP and ALT $(P<0.05)$ relative to the control. From the result of this experiment, it is concluded that administration of ethanolic extract of Sida acuta leaves may be toxic to Wistar rats at the doses administered.
\end{abstract}

Keywords - Biochemical, Liver, Microanatomy, Serum enzymes, Sida acuta,

\section{Introduction}

All over the world, particularly in developing countries of which Nigeria is one, the use of traditional plants for medicinal purposes is fast competing with the use of conventional drugs. More people are relying more and sometimes exclusively on plants for treatment of various illnesses and ailments (Ahmed et al., $2006)^{[1]}$.

Sida is traditionally used to cure diarrhoea in Australia. In Mexico, leaves are smoked for its simulative effects and in some parts of India, Sida leaves are used in tea for the same purpose. The plant is traditionally used as an astringent and as antidote for scorpion stings and snake bites. It has been reported that the roots of Sida contained 450ppm alkaloid including ephedrine, saponin, choline, pseudoephedrine, betaphenethytamine, hipaprhorine and related indole alkaloids (FAO, 2002) ${ }^{[2]}$. Kuniata and Rapp 2001 reported that it is because of the presence of different chemicals including alkaloids that arrow leaf Sida is not liked by cattle. This plant provides an excellent example for the elaboration of new simple preparations since its principal active constituent is due to one compound: cryptolepine. In addition, this alkaloid is known to exhibit various pharmacological activities like antitrypanosomal and antifungal effects (Ablordeppey et al 1999; Arzel et al., $2001)^{[3]}$, cytotoxic effect on cancerous cells lines probably by a direct DNA intercalating effect (Lisgarten et al $2002)^{[4]}$ and finally an antihyperglycemic activity (Bierrer et al 1998) ${ }^{[5]}$. In the Gold Coast, S. acuta plant is used to cure several diseases. The leaves when bruised are shiny and are put in the hands of midwives when they are about to remove death children from the womb and they are frequently used to procure abortion. (Prakash $e t$ al., 1987) ${ }^{[6]}$. The phytochemical studies of $S$. acuta leaves have revealed the presence of several constituents in ethanol extracts. Since various flavonoids have been reported to posses contraceptive properties (Anderson et al 1972 and Hariharan, 1980) ${ }^{[7]}$, and finally it is now evident that the plant has a good antiplasmodial activity due to its alkaloids cryptolepine the main alkaloid of the plant. It is also demonstrated that the plant is active in several bacterial strains and other compounds with interesting pharmacological properties (Karou et al 2007) ${ }^{[8]}$.

Some studies previously carried out have demonstrated the various pharmacological activities of the plant under study; however, there is a dearth of literature on the toxic effects of the plant on the histological architecture of the liver and some biochemical indices. This study is therefore seeking to determine possible toxic effect of ethanolic leaf extract of Sida acuta on the micro anatomy of liver 


\section{Introduction}

\section{Headings}

In Africa, medicinal plants still play an important role in health care. This is so because they are cheap and are locally available and efficient. The effects of medicinal plants are attributed to their content in active chemicals (Nacoulma, 1996) ${ }^{[9]}$. Many of these indigenous medicinal plants are used as spices and food plants. They are also added to foods meant for pregnant and nursing mothers for medicinal purpose (Okwu, 1999, $2001)^{[10]}$. Ethnobotanical investigation in some part of Africa has shown that species are traditionally used to treat various kinds of illnesses. Among such plants Sida acuta (Malvaceae) are the most frequently and widely put to use. Previous data showed that aqueous extract of $S$. acutai contains saponosides, coumarins, steroids, phenolic compounds and alkaloids (Konaté, 2010) ${ }^{[11]}$. However, in-spite of their interesting biochemical profiles, the toxicology and analgesic properties of these extracts are lacking, hence the aim of this research work is to evaluate the toxicity of ethanolic extract of $S$. acuta on the microanatomy and some biochemical parameters in adult Wistar rats.

\section{Materials and methods}

Thirty healthy Wistar rats with an average weight of $140 \mathrm{~g}$ were procured from the animal house of the Department of Pharmacology, University of Calabar, Calabar, Nigeria. The rats were kept and maintained under standard laboratory conditions of temperature, humidity and light for a period of two weeks in the animal holdings of the Department of Human Anatomy, University of Calabar, Calabar, before the commencement of the experiments. During this course, the rats freely fed on pellets from Ettems' feed holdings, Calabar and were given distilled water ad libitum.

\subsection{Experimental design and groupings}

In this study, a total of 30 adult Wistar rats were used. They were randomly separated into 3 groups of 10 rats each. Group B and C served as the experimental groups and received ethanolic extract of Sida acuta at varying doses. Group A served as the control group and received the same quantity of distilled water as contained in the experimental doses.

Administration of the ethanolic extract of Sida acuta was done orally by means of an oral canula. Group B and C received 100 and $200 \mathrm{mg} / \mathrm{kg}$ body weight for three weeks. Rats in the control group (Group A) received quantity of distilled water as contained in the experimental doses.

At the end of the study, the rats were sacrificed by cervical dislocation. The abdomen of each rat was carefully dissected, the liver removed and fixed in $10 \%$ formal saline for histological studies following the method of Carleton (1967).

\section{i. Histological observation}

\section{Result}

The effect of the extract on the cyto-architecture of the liver in this work was studied following method of Carleton (1967). Stained sections were examined using the light miscroscope $\mathrm{x} 400$ magnification.

The liver section of animals from group A control rats showed normal cytoarchitecture of the liver with polygonal hepatocyte radiating from a central vein, sparse collagenous tissue and sinusoid lining cells with their flattened condensed nuclei and poorly stained cytoplasm. (Plate 1)

Group B $(100 \mathrm{mg} / \mathrm{kgbw})$ : The liver tissues from this administered animals showed slight difference in their hepatic architecture. Nuclei were not prominent, but the overall integrity of the cells where maintained as compared to the control. (Plate 2)

The liver section from group C $(200 \mathrm{mg} / \mathrm{kgbw})$ administered rats revealed a distorted morphological features showing shrunken sinusoid, dilatation of the central vein and non prominent nuclei. (Plate 3 )

\section{ii. Liver serum enzymes (serum)}

Alanine aminotransferase (ALT) concentration

Group A animals showed normal level of ALT (54.24 \pm 4.22$)$

Group B animals showed ALT concentration significantly reduced $(\mathrm{P}<0.05)$ compared to the control group $(41.2 \pm 2.71)$

Group C animals showed reduced ALT concentration compared to the control group (44.71 \pm 4.20$)$ (Fig. 1)

\section{Aspartate aminotransferase (AST)}

Animals in group A revealed normal levels of AST $(25.53 \pm 1.0)$

Animals in group $\mathrm{B}$ showed reduced values that are significant $(\mathrm{P}<0.05)$ compared to the control group $(21.35 \pm 0.73)$ 
Animals in group $\mathrm{C}$ showed significantly reduced $(\mathrm{P}<0.05)$ values compared to the control group (11.79+0.55) (Fig. 2)

\section{Alkaline phosphate (ALP)}

Group A animals showed a normal level of ALP (77.99+4.40) Group B animals revealed a reduced value of ALP compared to control $(80.08+5.79)$

Group $\mathrm{C}$ animals showed significantly higher values $(\mathrm{P}<0.05)$ than the control group (95.34 \pm 1.34$)$ (Fig. 3)

\section{ii. Liver enzymes (tissue)}

\section{Alanine amiotransferase (ALT)}

Animal's tissues in the control group showed normal concentration of ALT $(52.16 \pm 1.34)$

Animal's tissues in group B revealed ALT concentration significantly $(\mathrm{P}<0.05)$ reduced compare to the control group (44.23+2.68)

Animal tissues in group C showed reduced concentration of ALT compared to the control group (44.71+4.20) (Fig. 4)

\section{Aspartate aminotransferase (AST)}

Tissues of group A animals showed normal concentration level of AST (29.82 \pm 2.11$)$.

Group B animal tissues revealed AST concentration significantly, lower $(\mathrm{P}<0.05)$ than the control $(11.52 \pm 0.45)$

Group C animal tissues showed AST concentration significantly $(\mathrm{P}<0.05)$ reduced compared to the control $(11.79 \pm 0.55)($ Fig. 5)

\section{Alkaline phosphatase (ALP)}

Group A animals revealed normal concentration of ALP in their tissues (105.12 \pm 5.22$)$

Group B animals showed significantly elevated concentration levels $(\mathrm{P}<0.05)$ of ALP in their tissues $(177.82 \pm 3.68)$

Group $\bar{C}$ animal's revealed lower concentration levels of ALP in their tissues that is significant $(\mathrm{P}<0.05)$ compared to the control group (95.34+1.34) (Fig. 6)

\section{Lates And Figures}

Plate 1: Photomicrograph of the liver from the control group fed with distilled water for 14 days using H\&E stain shows well defined central vein $(\mathrm{CV})$, Hepatocytes $(\mathrm{H})$ and $\operatorname{sinusoids}(\mathrm{S})$.

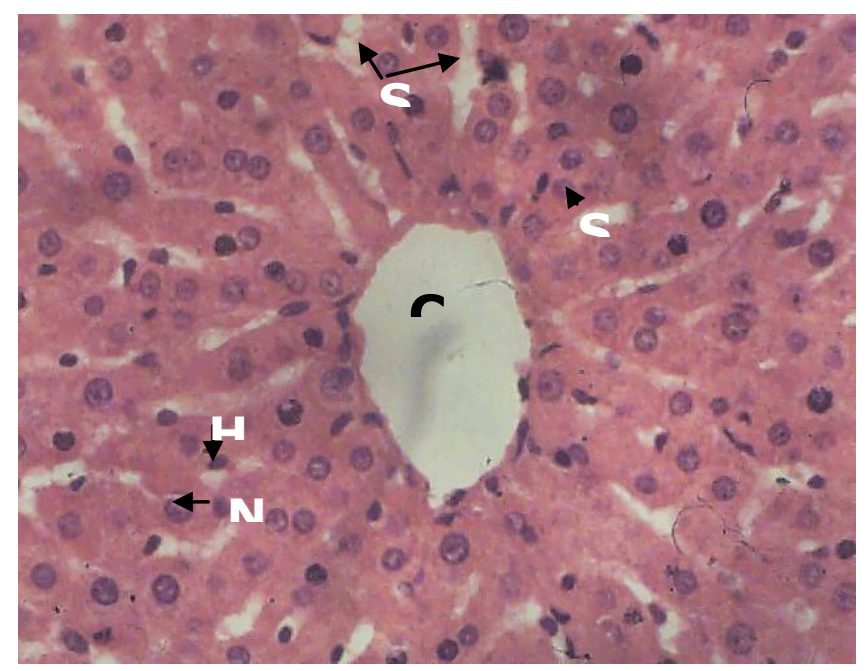

Figure 13: Comparison of liver tissue alkaline phosphatase levels in control and test groups.

Values are mean \pm SEM

*significantly different from control at $\mathbf{P}<0.05$.

$\mathrm{a}=$ significantly different from $100 \mathrm{mg} / \mathrm{kg}$ at $\mathrm{P}<0.05$ 
Plate 2: Micrograph section of liver from the group B administered animals, administered with the extract $(100 \mathrm{mg} / \mathrm{kgbw})$ for 14 days showing dilatation of sinusoid, degradation of the hepatocytes and pyknotic nuclei $\mathrm{H} \& \mathrm{E}$ stain $(\mathrm{X} 400)$

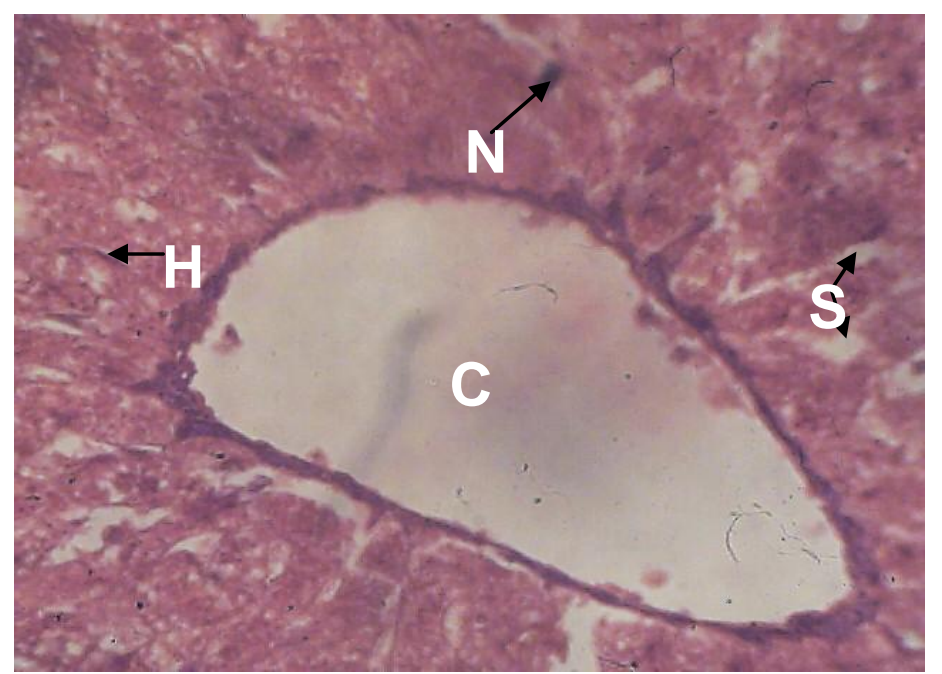

Plate 3: Micrograph section of the liver administered with $200 \mathrm{mg} / \mathrm{kgbw}$ of administered showed dilatation of the central vein $(\mathrm{CV})$, Nuclei $(\mathrm{N})$ not prominent, dilatation of the sinusoid $(\mathrm{S})$ and distortion of the hepatocyte (H). H \& E stain (X 400)
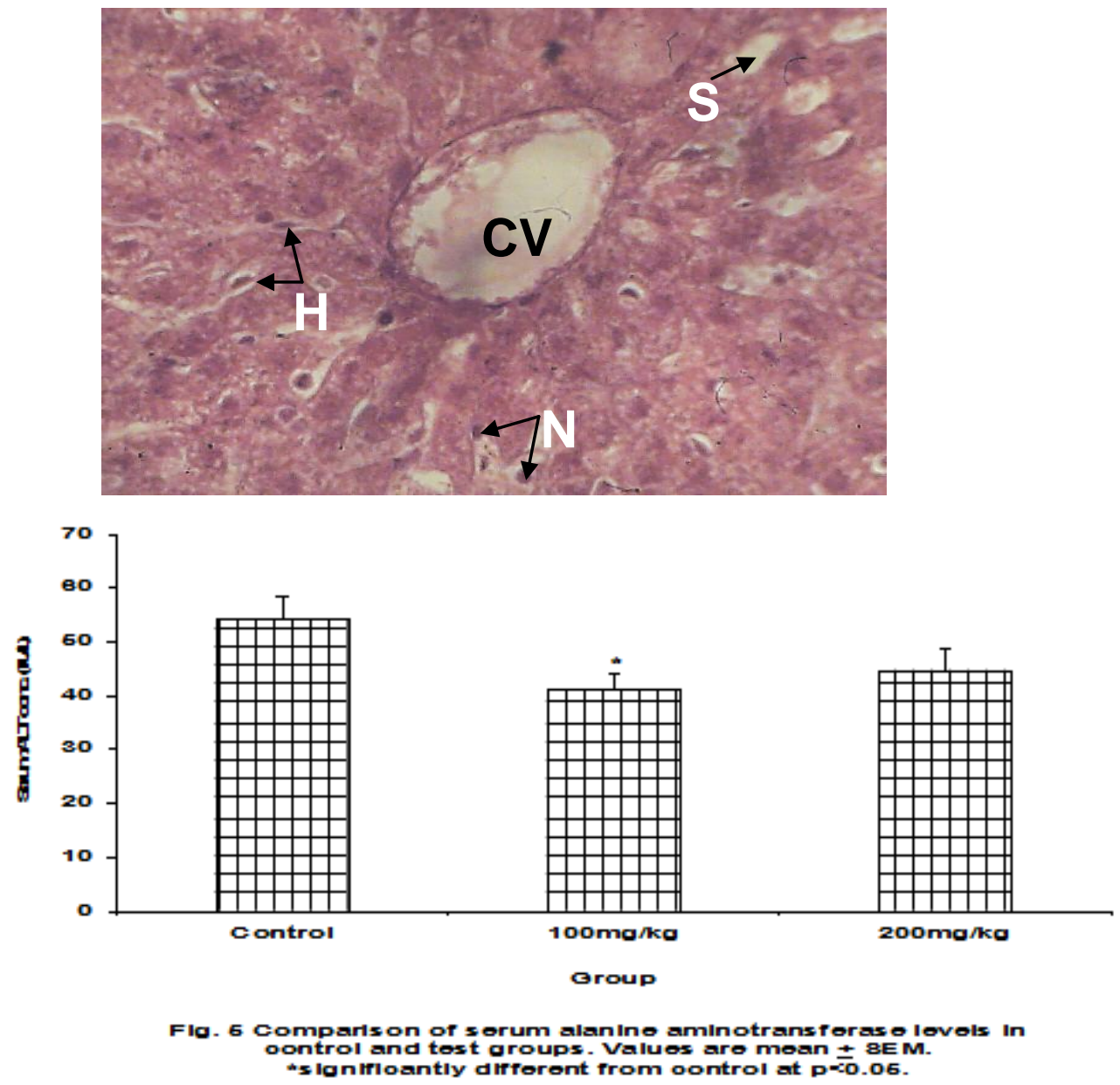

Fig .1: Comparison of serum alanine aminotransferase levels in control and test groups. Values are mean \pm SEM.

*Significantly different from control at $\mathrm{P}<0.05$ 


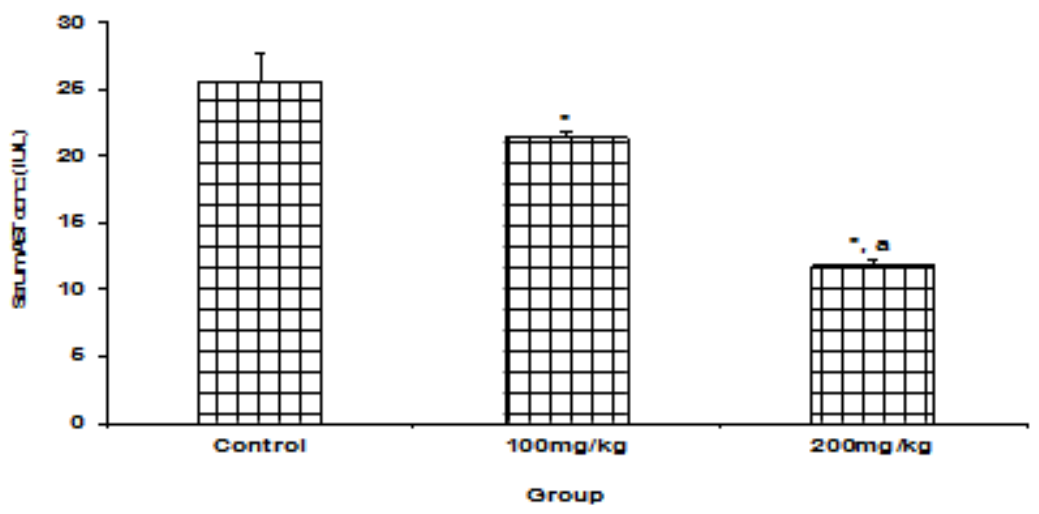

FIg. O Comparison of serum aspartate aminotransferase levels in

control and test groups. Values are mean $\pm 8 E M$.

= signiflcantly different from con trol at p<0.06.

Fig. 2: Comparison of serum aspartate aminotransferase levels in control and test groups.

Values are mean \pm SEM.

*Significantlv different from control at $\mathrm{P}<0.05$

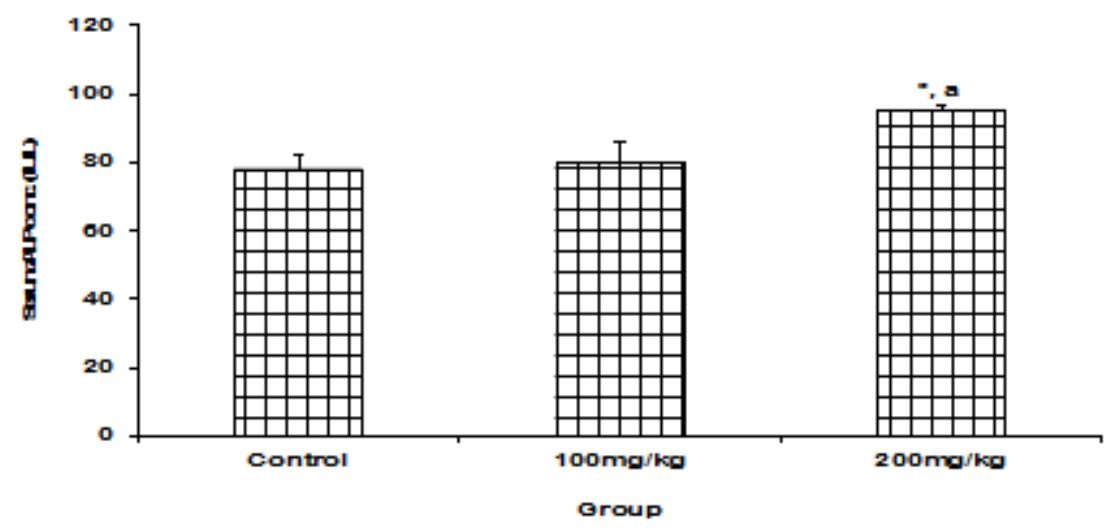

Flg. 7 Comparison of serum alkallne phosphatase levels in control and test groups. Values are mean + 8EM.

a = signiflcantly different from control at $p-0.06$.

Fig. 3: Comparison of serum alkaline phosphatase levels in control and test groups.

Values are mean \pm SEM.

*Significantly different from control at $\mathrm{P}<0.05$

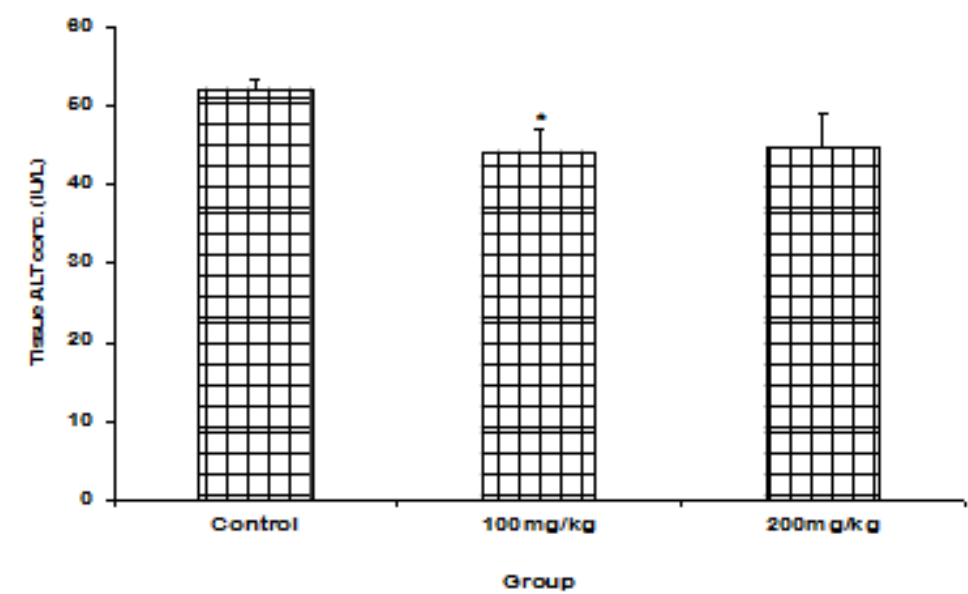

Fla. 8 Comparison of llver tiss ue a la nine aminotransferase levels

In oontrol and test groups. Values a ro moan $\pm 8 E M$.

Fig. 4: Comparison of liver tissue alanine aminotransferase levels in control and test groups. Values are mean \pm SEM 


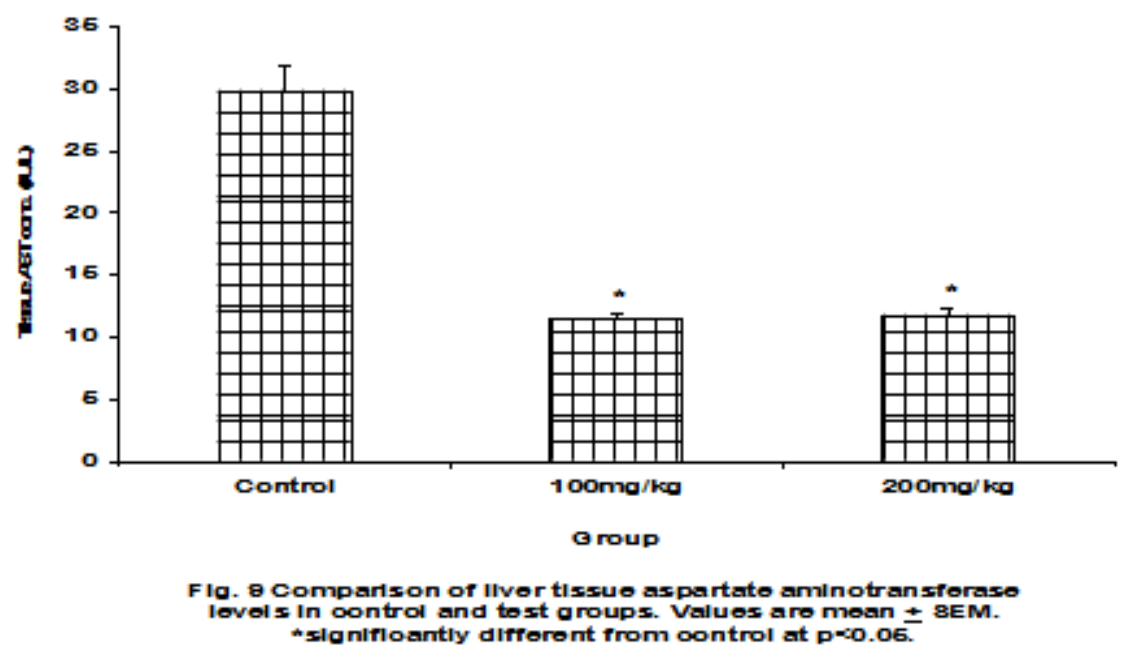

Figure 12: Comparison of liver tissue aspartate aminotransferase levels in control and test groups.

Values are mean + SEM

*significantly different from control at $\mathrm{P}<0.05$.

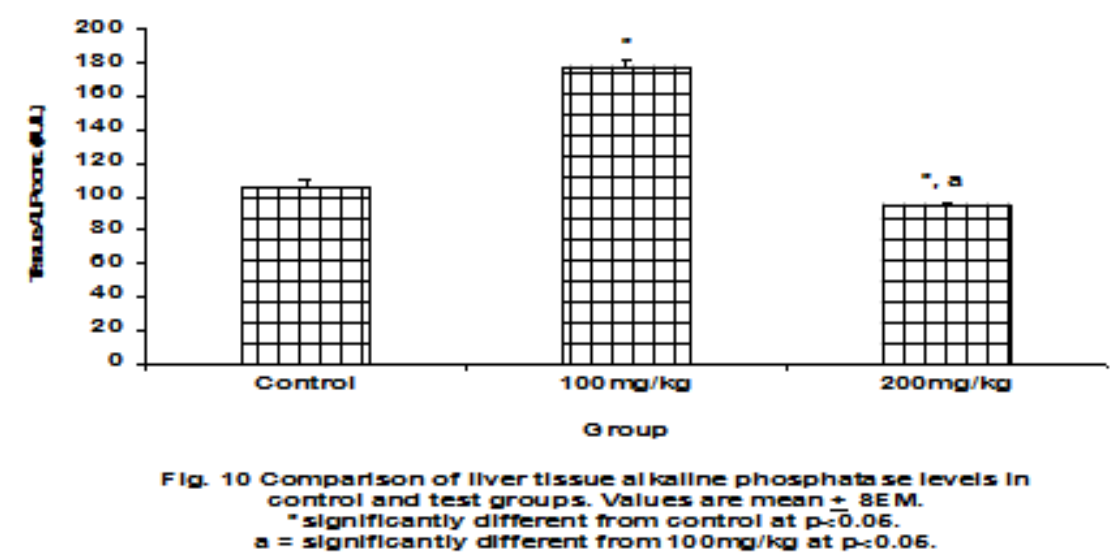

Figure 13: Comparison of liver tissue alkaline phosphatase levels in control and test groups.

Values are mean \pm SEM

*significantly different from control at $\mathrm{P}<0.05$.

$\mathrm{a}=$ significantly different from $100 \mathrm{mg} / \mathrm{kg}$ at $\mathrm{P}<0.05$

\section{Conclusion}

Sida acuta is a shrub belonging to the malvacea family and has been widely used as traditional medicine for the treatment of various ailments (Coee and Anderson, 1996; Caceres et al. 1987; Malairajan, 2006). Studies have demonstrated some biological activities exhibited by this plant (Bonjean et al. 2003; Dassonneville et al. 2000; Karou et al. 2003; Banzouzi et al. 2004) and also revealed the presence of active compounds (Dinan et al. 2001; Jang et al. 2003).

Histological section using H\&E revealed distorted morphological features such as shrunken sinusoid, dilatation of the central vein and vacoulations.

The liver plays a vital role in transforming and clearing chemicals and is susceptible to toxicity from these agents. Sometimes even when introduced within therapeutic ranges, these chemicals may injure the organ. Other chemical agents, such as those used in laboratories and industries, natural chemicals and herbal remedies can also induce hepatotoxicity. The human body identifies almost all drugs as foreign substances and subjects them to various chemical processes to make them suitable for elimination, though all tissues in the body have the same ability to metabolize chemicals. Smooth endoplasmic reticulum in the liver is the principal "metabolic clearing house" for both endogenous (chemicals, steroid, hormones, fatty acids and proteins) and exogenous substances (Friedman et al. 2003).

In the liver enzymes (serum) AST concentration for groups B and C showed significantly lower values compared to the control. The concentration of ALT in both group B and C also revealed values that are 
significantly $(\mathrm{P}<0.05)$ lower than control group. ALP concentration in group B did not reveal any marked difference compared to the control while as the group $\mathrm{C}$ showed significantly high levels compared to the control group. For the liver enzymes (tissue). AST concentration for groups B and C was significantly low compared to the control. ALT concentration in group B showed reduced values that are significant when compared to the control while as group $\mathrm{C}$ showed values that are reduced by not significant when compared to the control group. ALP concentration in groups B and C showed values that are significantly higher and lower respectively when compared to the control group.

Serum AST and ALT are sensitive indicators of liver damage or injury. The ratio of AST to ALT can be useful in differentiating between the causes of liver damage and elevated levels of AST are not specific for liver damage since it can also be used as a cardiac marker (Giboney, 2005). In this study, the observed reduction and elevation in the activity of ALT, AST and ALP in the administered animals is indicative of the fact that the extract has an adverse effect on the liver enzymes as it is reported that below normal values of liver enzymes may suggest liver dysfunction or insufficient protein intake (Palmer, 2004). Similarly Giboney, (2005) reported that any damage to the liver will cause medium elevation in the transaminases, however, very high elevations of the transaminases may suggest severe liver damage such as viral hepatitis, liver injury from lack of blood flow or injury from drugs or toxins. High elevations of the transaminases are frequently the first finding during hepatocellular damage and other toxicant are a measure of the pathological status of tissues (Gaw et al., 1995). Although there is no documented report on the effect of Sida acuta on liver enzymes, Parr and Bolwell, 2000; Scalbert, 2000 reported that the polyphenolic compounds present in Sida acuta plant which includes catechin and tannin exert anticarcinogenic, antimutagenic and cardioprotective effects linked to their free radical scavenging. However, high levels of ALP is an indication of a possible blockage of the bile duct, or injury to, or inflammation of the bile duct, in this condition ALP can overflow like a backed up sewer and seep out of the liver into the bloodstream (Palmer, 2004).

In view of the above reports, it can be concluded that ethanolic extract of Sida acuta is toxic when administered at a dose of $200 \mathrm{mg} / \mathrm{kgbw}$ to Wistar rats. Further studies should be carried out using the electron microscope on the cells of the liver. DNA assay of the liver cells should be undertaken.

More studies should be carried out particularly on the physiological parameters in relation to renal function with the aim of collaborating the findings from this present work.

\section{References}

[1] Ahmed, I. Agil,F \& Owais, M, Modern Phytomedicine. Turning Medicinal plants into drug west sussex John Wiley, 2006, 2-24.1

[2] Food \& Agriculture Organisation (Cultural practices. Fao.org/ag/AGP/AGPC/ publicat/FAOGULZ/B204 2002)

[3] Ablordeppey S Y, Fan P , Clark Ani \& Nimrod A, Probing the N-5 region of The indoquinoline lkaliod crytolepine for anticrytococcal Activity. Bioorganic \& medical chemistry. 7 (2), 1999, 343 -349

[4] Lisgarten J N, Coll M, portugal J, Wright Cw, Aymami J. The antimalarial \& cytotoxic drug cyptolrpine intercalates into DNA at cytosine-cytosin Sites .Nature Structural \& Molecular Biology 9, 2002, 57-60.

[5] Bierrer DE, Duberko LG,Zhang P,Lu Q imbach PA,Garofalo AW, Phuan pw ,fort DM,Litvak,Gerber E,Sloan B, Lou J, Cooper R ,Reaven GM, Antihyperglycemic Activities of cryptolepine analogues ; an ethno botanical Lead structure isolated from cryptolepis sanguinolenta Journal of medical chemistry 14, 1998, 2754-2764.

[6] Prakash, A. O. Shukla S \& Mathur R, Interceptive plant, present status \& future aspect. Compensation On Physical Ecology 12, $1987,157-162$.

[7] Coee FG, Anderson GJ, Ethnobotany in the garifuna of Estern Nicaragua Economic Botany. 50, 1996, $71-107$.

[8] Karou D, Nadembega WMC,Ouattara L,Iibiudo DP Canini A.Nikiema JB Simpora J, Colizzi V, Traore AS, African ethanopharmacology \& new drug discovery. Medical aromatic plant science biotechnology 1, 2007, 61-69.

[9] Nacoulma OG, Medicinal plants and their traditional uses in Burkina Faso, Ph.D Thesis, University of Ouagodougou, Burkina Faso, 1996.

[10] Okwu, D. E and Ochuko, P. O. Flavouring properties of species on cassava fufu. African Journal of Roots Tuber Crops, 3(2), 1999, 19-21.

[11] Okwu, D. E, Evaluation of the chemical composition of indigenous spices and flavouring agents. Global Journal of Pure Applied Science 7(3), 2001, 455-459

[12] Konaté K,Souza A,Polyphenol Contents, Antioxidant and Anti-Inflammatory Activities of Six Malvaceae Species Traditionally used to treat Hepatitis B in Burkina FasoEur J Sci ResYear: 201044570580 